\title{
Téoros
}

Revue de recherche en tourisme

\section{Le potentiel touristique des MRC du Québec : un essai de catégorisation}

\section{Claude Lamothe}

Volume 5, numéro 1, mars 1986

Tourisme et régions

URI : https://id.erudit.org/iderudit/1080592ar

DOI : https://doi.org/10.7202/1080592ar

Aller au sommaire du numéro

Éditeur(s)

Université du Québec à Montréal

ISSN

0712-8657 (imprimé)

1923-2705 (numérique)

Découvrir la revue

Citer cet article

Lamothe, C. (1986). Le potentiel touristique des MRC du Québec : un essai de catégorisation. Téoros, 5(1), 28-29. https://doi.org/10.7202/1080592ar d'utilisation que vous pouvez consulter en ligne.

https://apropos.erudit.org/fr/usagers/politique-dutilisation/ 


\section{Le potentiel touristique des MRC du Québec: un essai de catégorisation

\author{
par Claude Lamothe*
}

À l'occasion d'une brève enquête auprès des MRC, a l'automne 1984, dans le but de connaitre la place qu'elles faisaient au tourisme dans leur schéma d'aménagement, nous avons pensé qu'il serait intéressant de tenter une catégorisation selon leur potentiel touristique.

Nous profitons de ce numéro spécial de Téoros sur les régions touristiques du Québec pour livrer les résultats de l'exercice auquel nous nous sommes livrés.

\section{Les règles du jeu}

Nous allons au préalable établir les règles du jeu qui nous ont amené à catégoriser les MRC en trois grands groupes: ler groupe, MRC à fort potentiel: 2e groupe, MRC à potentiel moyen; $3 e$ groupe, MRC à potentiel faible.

Pour les fins de notre essai, le degré de potentiel touristique d'une MRC se détermine selon le potentiel d'attraction de ses ressources du milieu naturel et du milieu humain sur les marchés des clientèles des zones primaire, secondaire et tertiaire.

Mềme si dans une MRC, une seule municipalité locale a un fort potentiel touristique, on confere ce potentiel à l'ensemble de la MRC.

La catégorisation est faite en tenant compte du Québec globalement et non pas de la grande région touristique dans laquelle se situe la MRC. Done aucune pondération n'est faite pour relativiser le potentiel d'une MRC en regard du potentiel global de la région touristique dans laquelle elle se situe.

\section{Les catégories de MRC}

Les $M R C$ à fort potentiel touristique

Ce sont les MRC dont certains éléments du milieu naturel (mers, montagnes, lacs. forêts, faune, ete.) et/ou dont certains éléments du milieu humain (villes, campagnes, éléments patrimoniaux. équipements, infrastructures, etc.) sont de qualité telle qu'ils exercent une force d'attraction sur les zones de marché primaire (moins de 2 heu- res d'automobile), secondaire ( 2 at 5 heures d'automobile) et tertiaire (plus de 5 heures d automobile).

Ces MRC sont des zones de destination touristique actuelle ou éventuelle.

Les MRC a moven potentiel touristique Ce sont les MRC dont les éléments du milieu naturel et/ou du milieu humain sont de qualité telle qu'ils exercent une force d'attraction limitée aux zones de marché primaire et secondaire.

Souvent ces MRC servent de terrains de jeu et de lieux de villégiature pour les populations urbaines de la région immédiate et des régions périphériques.

Les MRC a faible potentiel touristique Ce sont les MRC dont les eléments du milieu naturel ev/ou du milieu humain sont de qualité telle qu'ils ont une attraction limitée à la zone primaire uniquement.

Souvent ces MRC n'ont qu'un rôle de desserte récréative pour les populations locales.

\section{Les résultats}

L'application des critères explicités cidevant et notre analyse des diverses régions du Québec nous amènent done à répertorier les MRC du Québec dans l'une ou l'autre des trois catégories.

La carte ci-contre localise chacune des 95 MRC et des trois communautés urbaines selon sa catégorie sur le territoire du Québec.

Il sera intếressant de vérifier ultếrieurement dans quelle mesure notre essai de catégoriation sera infirmé par les analyses objectives et scientifiques du potentiel touristique des MRC, en voie de realisation dans chaque région touristique du Québec.

\section{Potentiel} touristique des MRC du Québec

MRC a fort potentiel touristique

MRC á moven potentiel touristique

MRC à faible potentiel touristique

1 Therese-de-Blainville

2 Laval

3 L'Assomption

4 Champlain

5 La Vallèe-du-Richelieu

6 Les Maskoutains

7 Acton

8 Le Val Saint-Francois

9 Le Haut Saint-Francois

10 Le Granit

11 Vaudreuil-Soulanges

12 Beauhamois-Salaberry

13 Poussillon

14 Rouville

15 La Haute-Yamaska

16 Sherbrooke

17 Le Haut-Saint-Laurent

18 Les Jardins-de-Napierreville

19 Le Haut-Aichelieu

20 Brome-Missisquoi

21 Memphrémagog

22 Costicook

23 Communauté Urbaine de Montréal

24 Lajemmerais

"L'auteur, aménapiste, est plessden et directeur géné. ral de SOTAR Inc. 


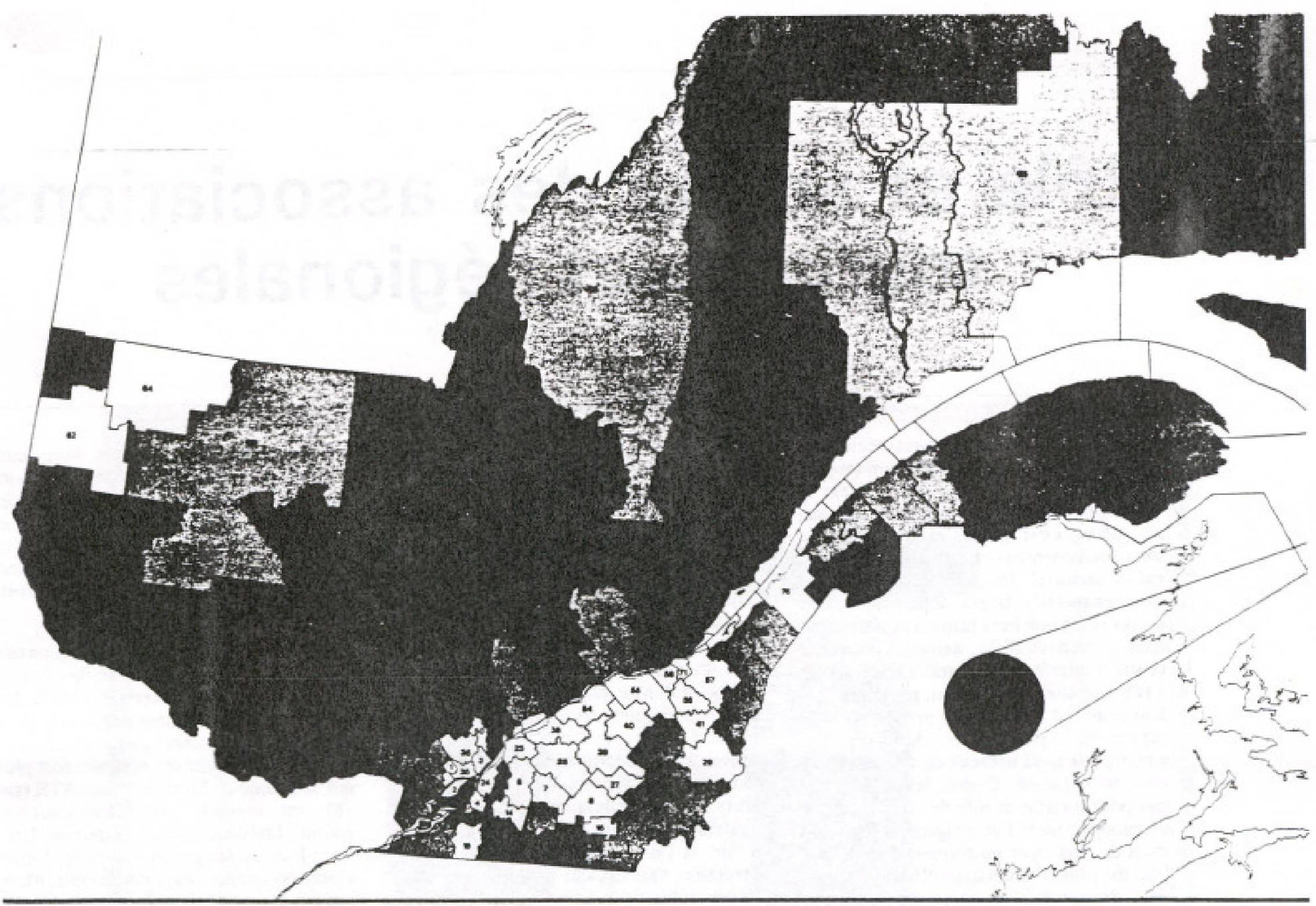

25 Le Bas-Richelieu

26 Drummond

27 L'Or Blanc

28 L'Amiante

29 Beauce-Sartigan

30 Communauté Régionale de l'Outaouais

31 Papineas

32 Argenteuil

33 Deux-Montagnes

34 Mirabel

35 Des Moulins

36 Montcalm

37 D'Autray

38 Nicolet-Yamaska

39 Arthabaska

40 L'Ërable

41 Robert-Cliche

42 Les Etchemins

43 Pontiac

44 La vallee-de-la-Gatineau

45 Antoine-Labelle

46 Les Laurentides

47 Les Pays-d'en-Haut

48 Matawinie

49 La Riviére-du-Nord
50 Joliette

51 Maskinonge

52 Le Centre-de-la-Mauricie

53 Francheville

54 Bécancour

55 Lotbiniere

56 La Nouvelle-Beauce

57 Bellechasse

58 Les Chutes-de-la-Chaudière

59 Montmagny

60 L'islet

61 Témiscamingue

62 Rouyn-Noranda

63 Abitibi-Ouest

64 Abtibi

65 La vallée de l'Or

66 Le Haut-Saint-Maurice

67 Mékinac

68 Portneuf

69 La Jacques-Cartier

70 Communauté Urbaine de Quebec

71 Desjardins

72 L'lle d'Orléans

73 La Cóte-de-Beaupré

74 Charlevoix.
75 Charlevoix-Est

76 Kamouraska

77 Riviere-du-Loup

78 Témiscouata

79 Les Basques

80 Rimouski-Neigette

81 La-Mitis

82 Matane

83 La Matapédia

84 Avignon

85 Denis-Riverin

86 Bonaventure

87 La Côte-de-Gaspé

88 Pabok

89 Le Domaine-du-Roy

90 Maria-Chapdelaine

91 Lac Saint-Jean-Est

92 Le Fjord-du-Saguenay

93 La Haute-Côte-Nord

94 Manicouagan

95 Caniapiscau

96 Sept-Aivières

97 Minganie

98 Les lles-de-la-Madeleine $f$ 